\title{
Preparation and characterization of liposomes loaded with silver nanoparticles obtained by green synthesis
}

\author{
Joel Toribio Espinoza ${ }^{\oplus 1}$, Robson Schimandeiro Novak ${ }^{1}$, \\ Cássia Gonçalves Magalhães ${ }^{2}$, Jane Manfron Budel ${ }^{1}$, Barbara Justus ${ }^{1}$, \\ Melissa Marques Gonçalves ${ }^{3}$, Patricia Mathias Döll Boscardin' ${ }^{1}$, \\ Paulo Vitor Farago ${ }^{1}$, Josiane de Fátima Padiha De Paula ${ }^{1}$
}

${ }^{1}$ Postgraduate Program in Pharmaceutical Sciences, State University of Ponta Grossa, Ponta Grossa, PR, Brazil, ${ }^{2}$ Department of Chemistry, State University of Ponta Grossa, Ponta Grossa, PR, Brazil, ${ }^{3}$ Postgraduate Program in Pharmaceutical Sciences, Federal University of Parana, Curitiba, PR, Brazil

\begin{abstract}
The objective of this work was to develop and characterize liposomes loaded with silver nanoparticles (LAgNPs) to show improvement in stability characteristics. AgNPs were prepared by the green synthesis method with Aloe vera gel extract and exposure to sunlight. Liposomes were prepared by the modified reverse phase method. Particle size, polydispersity index, zeta potential, as well as the scanning electron microscopy (SEM) morphological aspects of AgNPs and LAgNPs were evaluated. In addition, was used flame atomic absorption spectroscopy to determine the amount of AgNP that was encapsulated in liposomes. The AgNPs presented as amorphous and polydisperse structures, with a mean diameter of $278.46 \mathrm{~nm}$ and zeta potential of $-18.3 \mathrm{mV}$. LAgNPs had a mean diameter between 321 and $373 \mathrm{~nm}$, the polydispersity index close to 0.2 and a zeta potential around $-40 \mathrm{mV}$, which indicates greater stability to the AgNPs. The images obtained by SEM show semicircular structures for AgNPs and well-defined spherical shape for LAgNPs. The percentage of encapsulation was between 51.81 to $58.83 \%$. These results showed that LAgNPs were obtained with adequate physicochemical characteristics as a release system.
\end{abstract}

Keywords: Silver nanoparticles. Aloe vera. Sunlight. Liposomes.

\section{INTRODUCTION}

Silver nanoparticles (AgNPs) have become the nanomaterials with the highest degree of commercialization due to their broad-spectrum antimicrobial activities (Alarcon et al., 2012; Johnston et al., 2010; Sharma, Yngard, Lin, 2009). In addition, the anti-fungal, anti-biofilm, anti-inflammatory, antithrombotic and anti-fungal effects also improve wound healing (Panacek et al., 2009; Ragaseema et al., 2012). AgNPs have also been explored as nanoprobes for the detection and imaging of tumors, drug delivery

*Correspondence: J. T. Espinoza. Universidade Estadual de Ponta Grossa, 4748. Carlos Cavalcanti Avenida, 84030-900. Ponta Grossa, PR, Brazil. Tel: +55 42 999714227. E-mail: baritono45@gmail.com vectors, as well as inhibitors, angiogenesis suppressors and tumor growth (Liu et al., 2012). AgNPs have also shown great potential in the area of cancer treatment because they are selectively involved in the breakdown of the mitochondrial respiratory chain, leading to the production of reactive oxygen species (ROS) and disruption of adenosine triphosphate (ATP) synthesis (Guo et al., 2015).

The various techniques of AgNP synthesis generate interest in the research of this material, especially the green synthesis, for its advantages over conventional methods. It is cost-effective, environmentally harmless, and easily transposed to industrial scale synthesis (Sharma, Yngard, Lin, 2009; Sulaiman et al., 2013). The plants or products derived therefrom present a wide variety of metabolites with potential redox, and which 
play an important role as a reducing agent in the biogenic synthesis of silver (Keat et al., 2015).

Some bioactive molecules and benzoquinones in plant extracts such as Aloe vera could act as reducing agents for the formation of metallic nanoparticles (Zhang et al., 2010). Mostly the gel that is found in the central part of the plant is used for extraction of the phytochemical compounds. The green colored gel near the parenchyma contains aloin, which is considered as the main stabilizing agent and also emodin, which is a phytochemical reducing agent. This plant extract has already been used to synthesize AgNPs (Sadhasivam, Durairaj, 2014).

Ultraviolet (UV) radiation photoreduction, also considered as green synthesis, is a simple and effective method for the production of silver and gold nanoparticles. Irradiation allows AgNPs to form in smaller sizes, in addition to a uniform homogeneous distribution of uniform size (Maillard, Huang, Brus, 2003).

The activation by photosensitization of aromatic compounds, the nucleation, which involves the role of photosensitized aromatic compounds, and the reduction of silver ions, could be the mechanism for the synthesis of AgNPs (Gade et al., 2014).

It is important to note that in the synthesis of AgNPs there is no need to use high pressure, energy, temperature and toxic chemicals such as sodium borohydride, which may have adverse effects on medical applications (Sulaiman et al., 2013), therefore being easier its application and later a possible production in increased scales.

Due to the high reactivity of AgNPs, the aqueous solutions of AgNPs are not stable and rapidly agglomerate. Stabilizing agents are used to separate the particles to prevent aggregation (Barani et al., 2010). Liposomes have been reported to improve the biocompatibility and stability of metal nanoparticles (Barani et al., 2010; Eid, Azzazy, 2014).

Liposomes are nanoparticulate systems that have been adopted by several researchers as the system of release of choice for the administration of drugs, vaccines and targeting of therapeutic agents (Gregoriadis, 1995; $\mathrm{Li}, \mathrm{An}, 2014)$. Because of their unique composition and structure, liposomes have a number of favorable features, including high biocompatibility, biodegradability, high drug transportability and easily adjustable handling properties (Zhu et al., 2014). Liposomes present as an option capable of transporting AgNPs (Barani et al., 2011; Eid, Azzazy, 2014).
The conventional liposome composition consists of a lipid bilayer which may be composed of cationic, anionic or neutral phospholipids and cholesterol, which encloses an aqueous core. cholesterol is an important biomolecule for cell membrane function because of its ability to control the fluidity of the lipid membrane. cholesterol is often added to phospholipid liposomes to improve stabilization (Aramaki et al., 2016). Both the lipid bilayer and the aqueous space may incorporate hydrophobic or hydrophilic compounds, respectively.

Thus, considering the importance of the constant search for new systems with potential antitumor and/or antimicrobial action, as an alternative to conventional treatments, this work proposes the development of liposomes loaded with silver nanoparticles obtained by the green synthesis method.

\section{MATERIAL AND METHODS}

\section{Reagents and solvents}

Silver nitrate $99.8 \%$ was purchased from BIOTEC, cholesterol $94 \%$ and chloroform P.A. ACS $99.8 \%$ and L- $\alpha$-phosphatidylcholine $\geq 99 \%$ egg yolk from SIGMAALDRICH; All other reagents are of analytical grade obtained from the local supplier. Purified Water Milli-Q (MILLIPORE) was used throughout the study.

\section{Preparation of the aqueous extract of Aloe vera gel}

The aqueous extract of Aloe vera gel was prepared according to the reports of some authors (Ashraf et al., 2016; Sadhasivam, Durairaj, 2014; Zhang et al., 2013), with minor modifications. Fresh, healthy leaves were harvested from the University of Ponta Grossa (UEPG) garden and carefully washed with tap water followed by distilled water to remove any dust and visible undesirable particles, then dried at room temperature to remove water from the surface of the leaves, and the gel was carefully removed. Then, $10 \mathrm{~g}$ of this gel was transferred to a $250 \mathrm{~mL}$ beaker containing $100 \mathrm{~mL}$ of distilled water, homogenized in ultraturrax and heated to $80^{\circ} \mathrm{C}$ for 20 minutes. It was allowed to cool to room temperature, and then the gel was centrifuged at 12,000 rpm for $15 \mathrm{~min}$ at $4^{\circ} \mathrm{C}$ and filtered on a $0.22 \mu \mathrm{m}$ pore syringe filter. The filtrates were then stored at $4-8^{\circ} \mathrm{C}$ and used as reducing and stabilizing agents in the synthesis of AgNPs. 


\section{Synthesis of silver nanoparticles (AgNP)}

For the synthesis of the AgNPs, an aqueous solution of $1 \mathrm{mM}$ silver nitrate (AgNO3) was prepared. Then, $10 \mathrm{~mL}$ of Aloe vera gel extract was added to 90 $\mathrm{mL}$ of $1 \mathrm{mM}$ aqueous $\mathrm{AgNO} 3$ solution and the mixture was exposed to sunlight at noon for 30 seconds to one minute. In addition, a control experiment was analyzed to understand the participation of Aloe vera gel extract in the reaction; the control was composed of $1 \mathrm{mM}$ $\mathrm{AgNO}_{3}$ solution without extract and sunlight exposure for 1 hour. The complete reduction of $\mathrm{AgNO} 3\left(\mathrm{Ag}^{+}\right.$ ions) was confirmed by the color change from colorless to colloidal brownish yellow $\left(\mathrm{Ag}^{0}\right)$. The solution was then stored in the dark at a temperature of $4-8{ }^{\circ} \mathrm{C}$ for further analysis and incorporation into liposomes. The formation of AgNPs was further confirmed by UV-Vis spectrophotometer analysis (NIR VARIAN CARY 50).

\section{Synthesis of liposomes}

Liposomes were prepared by the reverse phase evaporation method (Szoka, Papahadjopoulos, 1978). Liposome suspensions $(0.9 \mathrm{mg} / \mathrm{mL})$ were prepared using L- $\alpha$-phosphatidylcoline (PC) and cholesterol (Cho) in different molar ratios (2:1, 4:1, 8:1 and 16:1). Lipid solutions at $1 \times 10^{-2} \mathrm{~mol} / \mathrm{L}$ were used. Thus, the heavy lipids were dissolved in $5 \mathrm{~mL}$ of chloroform. The organic solution was added slowly with the aid of a syringe coupled to the disposable $27 \mathrm{G} \mathrm{5/8}$ "needle on the aqueous phase (FO 1:10 FA, v/v, organic phase: aqueous phase) (Low et al., 2013), while the aqueous phase was in the ultrasonic bath $(15 \mathrm{~min})$ providing opalescent and homogeneous dispersions (40 kHz Ultrasonic Frequency and 135 Watts Ultrasonic Power). The aqueous phase consisted of sterile distilled water (PC: Cho) or AgNPs solution (LAgNPs). The organic solvent was evaporated in a rotary evaporator at $55^{\circ} \mathrm{C}$ and $25 \mathrm{rpm}$ under vacuum (Eid, Azzazy, 2014). When the AgNPs solution was used in the aqueous phase, the whole process was carried out in the dark.

The lipid emulsion was reconstituted with water to the initial volume and sonicated in the ultrasonic bath for 15 minutes, forming the liposomal vesicles. This solution was filtered at $0.22 \mu \mathrm{m}$ to remove nonassociated AgNPs and lipid aggregates. The solution was then centrifuged at $8,000 \mathrm{rpm}$ for 15 minutes at 4 ${ }^{\circ} \mathrm{C}$. The supernatant was removed and the precipitate was reconstituted with distilled water to initial volume and stored in the refrigerator at $4-8^{\circ} \mathrm{C}$.

\section{Determination of mean diameter and zeta potential}

The size and polydispersity index were determined by dynamic light scattering with ZETASIZER NANO SERIES (MALVERN Instruments), model NANO ZS90, with a detection angle of $90^{\circ}$ at $25{ }^{\circ} \mathrm{C}$. The suspensions were diluted with distilled water $(1: 10)$ and analyzed in triplicate. The samples were also diluted in the same manner for zeta potential analysis.

\section{Analysis by UV-Vis spectroscopy}

The reduction of silver ions to the nanoparticle form was monitored by observing the UV-Visible spectrum of the silver nanoparticle solutions. The AgNPs solution spectra were monitored by a VARIAN CARY 50 NIR UV-VIS spectrophotometer without dilutions in the 200$800 \mathrm{~nm}$ range. The blank was calibrated with distilled water intended to prepare the nanoparticle suspensions and the samples were analyzed directly.

\section{Scanning Electron Microscopy (SEM)}

The morphological and surface evaluation of the nanoparticles and liposomes was performed in a scanning electron microscope with field emission MYRA $3 \mathrm{LMH}$ (Tescan). $10 \mu \mathrm{L}$ of the silver nanoparticle suspensions and $10 \mu \mathrm{L}$ of the 1:10 dilution of the LAgNP suspensions in the sample holder were added and oven dried at $36{ }^{\circ} \mathrm{C}$ for 24 hours. The samples were metalized with gold on the SC7620 mini sputter Coater and the micrographs were obtained after visualization of the samples, using acceleration voltages between 10 and 25 $\mathrm{kV}$. In addition, energy-dispersive spectroscopy (EDS) was used to determine the presence of AgNPs within the liposomes. The recording of the images occurred through the equipment software.

\section{Analysis by Fourier-transform infrared spectroscopy (FTIR)}

The nanoparticles and liposomes were analyzed by FTIR to evaluate the functional groups that may be involved in the formation of nanoparticles or interacting in the liposomes. For each sample, tablets were prepared by cold pressing using a pad and a manual hydraulic 
press. The potassium bromide pellet was mixed with lyophilized samples of aqueous Aloe vera gel extract, AgNP, LAgNP or PC: Cho in an amount of $4 \mathrm{mg}$ of each sample and $196 \mathrm{mg}$ of spectroscopic grade $\mathrm{KBr}(2 \%$ $\mathrm{m} / \mathrm{m}$ ) (Sigma Aldrich), for reading the IRPrestige-21 (Shimadzu) equipment, with parameters of 64 scans. $\mathrm{min}^{-1}$ and $4 \mathrm{~cm}^{-1}$ resolution, considering the experimental window of interest of 4000-400 waves. $\mathrm{cm}^{-1}$; and reference reading with pure $\mathrm{KBr}$ pellet, as baseline.

\section{Silver Determination by Atomic Absorption Spectrometry with Flame (FAAS)}

The concentration of silver in the solutions of AgNPs or LAgNPs synthesized was determined in the Flame Atomic Absorption Spectrophotometer(VARIAN AA240FS). The analytical curve was prepared with the standard silver solution (Mexico, 2001). To prepare the standard, $0.1575 \mathrm{~g}$ of silver nitrate $\left(\mathrm{AgNO}_{3}\right)$ was dissolved in $100 \mathrm{~mL}$ of water, $10 \mathrm{~mL}$ of concentrated nitric acid was added and the mixture was quenched to $1000 \mathrm{~mL}$ with water $(1 \mathrm{~mL}=100 \mu \mathrm{g} \mathrm{Ag})$. The VARIAN SPECTRAA software programmed the conditions, for which a 10 ppm solution was inserted into the equipment. Subsequently, the equipment made the dilutions with ultrapure water and elaborated the calibration curve in five concentrations (2, 4, 6, 8 and $10 \mathrm{ppm})$ automatically, the analysis was done in five times. The equation of the line and the correlation coefficient (r) were determined and the data were analyzed using Excel software. The characteristic wavelength of silver is $328.1 \mathrm{~nm}$.

The AgNP or LAgNP solutions were submitted to matrix elimination through acid digestion to avoid interfering with the final analysis, the use of $2 \%$ nitric acid was used (Escobar, 2015; Paluri, 2011; Ramírez, 2010). Thus, $1 \mathrm{~mL}$ of the AgNP or LAgNP solution was added $1 \mathrm{~mL}$ of $2 \%$ nitric acid and stored for 24 hours, then it was filled to $10 \mathrm{~mL}$ with distilled water for reading in the equipment for triplicate.

\section{Determination of liposome encapsulation efficiency}

The efficiency of liposome encapsulation was measured using a flame atomic absorption spectrophotometer, so $10 \mathrm{~mL}$ of a dilute solution $\left(10^{-1}\right)$ of LAgNPs was injected into the system and the percentage of encapsulated AgNPs was calculated using Equation 1 (Eid, Azzazy, 2014).

$$
E E \%=\frac{N T-N F}{N F} \times 100 \% \quad(\text { Equation } 1)
$$

Where NT is the total of silver nanoparticles added to the liposomes, and NF is the portion of free or unencapsulated AgNPs present in the supernatant after centrifugation of LAgNP at 12,000 rpm for 15 minutes at $4{ }^{\circ} \mathrm{C}$.

\section{Statistical analysis}

The statistical significance of the differences in particle size, polydispersity index and Zeta potential of AgNP and LAgNPs was calculated by Student's t-test for paired samples, Anova and Tuckey. The data obtained were statistically analyzed and the results were expressed as a mean \pm standard deviation (SD). Differences were considered significant at $p<0.05$. All tests were performed using the IBM SPSS STATISTICS 20 and BIOESTAT 5.0 software.

\section{RESULTS AND DISCUSSION}

\section{Synthesis of silver nanoparticles (AgNPs)}

It was possible to observe the formation of silver nanoparticles by the reduction of ionic silver by the extract of Aloe vera gel associated to the sun exposure in different periods of time. The appearance of different colorations (Figure 1), indicates the formation of AgNPs with different sizes as a function of the time of sun exposure (Tang et al., 2014). The reaction ends when all the silver agglomerates and precipitates (Cruz et al., 2012).

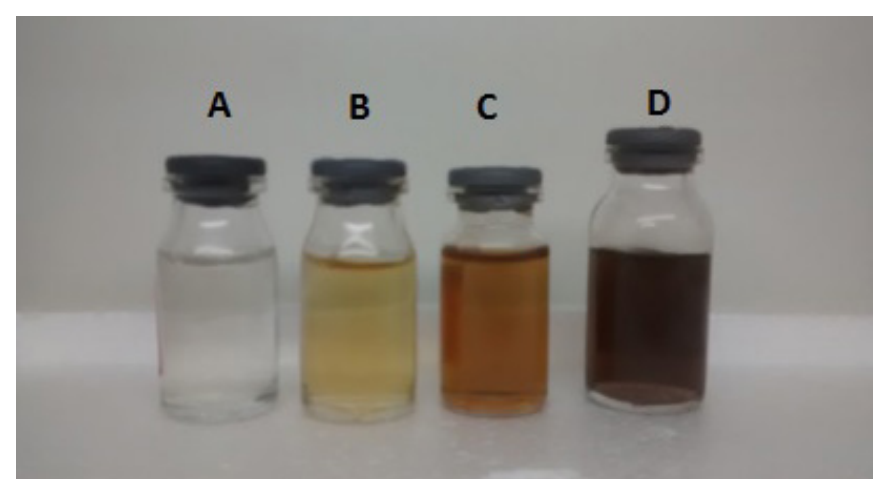

FIGURE 1 - Colorations of AgNPs solutions depending on the time of sun exposure. (A) No exposure, (B) between 5 seconds and 1 minute, $(C)$ between 2 and 5 minutes and (D) more than 5 minutes. 
The appearance of color in the course of the reaction is due to the excitation of surface plasmon resonance vibrations, and the absorption at a wavelength between 400 and $500 \mathrm{~nm}$ represents the spectroscopic identification of the formation of AgNPs (Ashraf et al., 2016; Cruz et al., 2012).

Many authors have described biosynthesis of silver nanoparticles by photoinduction, with extracts of several plants (Kumar et al., 2016a, 2016b), all of these studies showed a decrease in reaction time when exposed to radiation.

\section{Synthesis of liposomes}

The technique of liposome and LAgNPs production proved to be easy to perform, resulting in homogeneous solutions and no precipitation after filtration (Figure 2). This homogeneity indicates that cholesterol, which is insoluble in water, lies within the lipid bilayer of the liposome.

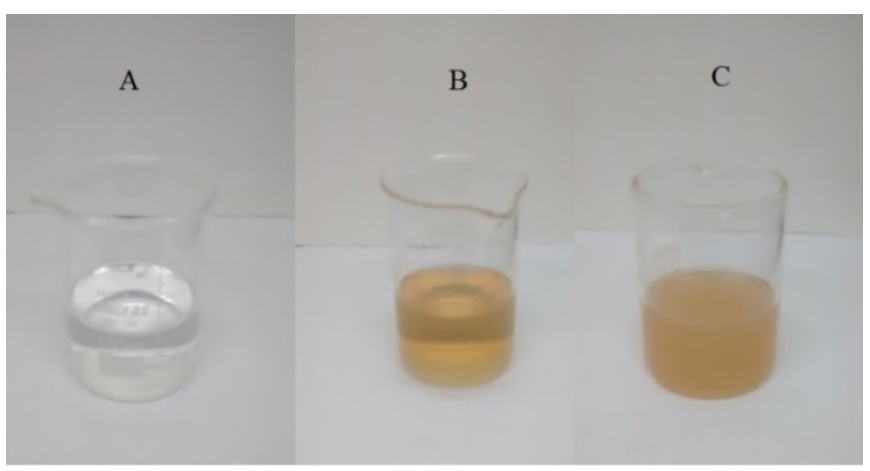

FIGURE 2 - Photography of solutions from AgNP and LAgNP. (A) AgNO3 solution mixed with Aloe vera extract without exposure to sunlight, (B) AgNPs solution and (C) LAgNPs solution.

Eid and Azzazy (2014) developed a work reporting the encapsulation of AgNPs in liposomes using the modified reverse phase evaporation method, which allowed the preparation of nanoliposomes without the need for a high-pressure homogenizer or extruder, similar to the method used in this work.

One of the main problems in obtaining AgNPs is the instability of the nanoparticles produced due to their easy oxidation (Mukha et al., 2013). However, in the present study, it was observed that AgNPs were stabilized when encapsulated in liposomes, resulting in a narrower distribution of sizes (Table II).

\section{Determination of the mean} diameter and zeta potential

Table I summarizes the mean diameter (MD) data determined by intensity distribution. Also are described the polydispersity index (PDI) and Zeta potential (ZP) of the AgNPs developed in relation to the time of exposure to sunlight.

TABLE I - Distribution of MD, PDI, and PZ of AgNPs synthesized at different times of exposure to sunlight

\begin{tabular}{lccc}
\hline $\begin{array}{l}\text { Exposure time } \\
\text { to sunlight }\end{array}$ & $\begin{array}{c}\text { AgNPs } \\
\text { MD }(\mathbf{n m}) \pm \text { SD }\end{array}$ & PDI \pm SD & $\begin{array}{c}\text { ZP (mV) } \\
\pm \text { SD }\end{array}$ \\
\hline 5 seconds & $129,12 \pm 47,99$ & $0,396 \pm 0,02$ & $-14.3 \pm 5.63$ \\
10 seconds & $182,43 \pm 11,98$ & $0,384 \pm 0,02$ & $-9.21 \pm 4.6$ \\
15 seconds & $194,63 \pm 34,26$ & $0,407 \pm 0,01$ & $-14.9 \pm 6.10$ \\
30 seconds & $278,46 \pm 85,71$ & $0,481 \pm 0,13$ & $-18.96 \pm 10.0$ \\
1 minute & $339,03 \pm 121,68$ & $0,702 \pm 0,25$ & $-14.6 \pm 11.4$ \\
2 minutes & $344,06 \pm 150,77$ & $0,880 \pm 0,09$ & $-13.1 \pm 12.0$ \\
\hline
\end{tabular}

The PDI is a measure of the size distribution amplitude resulting from the cumulative analysis of dynamic light scattering (DLS) data, whose values are between 0 and 1. A PDI of 1 indicates large variations in particle size, whereas a value close to 0 indicates a population of monodisperse particles (Lacatusu et al., 2012). All AgNPs were polydispersed, with PDI above 0.384. However, the AgNPs synthesized with sun exposure over 1 minute were more polydisperse because they had a PDI higher than 0.7.

The MD results confirmed the synthesis of AgNPs, and the intensity measurement shows that the nanoparticles formed in the first 30 seconds of sun exposure have sizes between 129.12 and $278.46 \mathrm{~nm}$. The $\mathrm{ZP}$ values of AgNPs synthesized with Aloe vera extract and 30 seconds of sun exposure (AgNP30s) were -18.96 $\mathrm{mV}$. Particles can be considered stable when the absolute value of $\mathrm{PZ}$ is close to $|30| \mathrm{mV}$, while $\mathrm{PZ}$ near 0 and $|5|$ $\mathrm{mV}$ can produce flocculation phenomena more easily (Neves et al., 2013). However, Sadhasivam and Durairaj 
(2014), obtained stable AgNPs with $\mathrm{ZP}$ of $-18.3 \mathrm{mV}$, similar to that obtained in this study.

The DM, PDI and PZ distribution of the LAgNPs, shortly after the preparation and after 2 months of storage, are shown in Table II.

It is observed that all formulations evaluated immediately after preparation and after 60 days of storage presented adequate PDI values, indicating a low polydispersity and homogeneity of sample sizes.

It is also possible to observe a high $\mathrm{ZP}$, around -40 $\mathrm{mV}$, which reduces the possibility of self-aggregation and indicates greater stability of all LAgNPs. The ZP value of the AgNP30s prior to their incorporation into the liposomes was $-18.6 \mathrm{mV}$, this considerable increase in the $\mathrm{ZP}$ value is of fundamental importance to ensure greater stability to the AgNP30s.

This negative ZP value was also found by Aramaki et al. (2016) in liposomes prepared with soy lecithin and without cationic surfactants. The negative zeta potential of lipids was also observed in several studies (Barani et al., 2010; Eid, Azzazy, 2014; Katagiri et al., 2007).

Statistical analysis, using the Tukey ANOVA test $(p>0.05)$ showed that, when compared to the different molar ratios, the newly prepared LAgNPs presented statistically different MD and PDI, but the zeta potential did not present a significant difference. The same result was obtained in the comparison of LAgNPs after 2 months of storage.

To evaluate the stability of the samples after 2 months of storage, Student's t-test for paired samples was applied. The results indicated that the LAgNP8:1 formulations are stable since they did not show a statistically significant difference $(p>0.05)$ after 2 months of storage in the MD, PDI and ZP parameters.

TABLE II - Distribution of MD, PDI, and ZP of the LAgNPs in different molar ratios of PC:Cho after preparation and after 60 days

\section{Samples analyzed after preparation}

\begin{tabular}{|c|c|c|c|}
\hline Sample & $\mathrm{MD}(\mathrm{nm}) \pm \mathrm{SD}$ & $\mathrm{PDI} \pm \mathrm{SD}$ & $\mathrm{ZP}(\mathrm{mV}) \pm \mathrm{SD}$ \\
\hline LAgNP(PC:Cho, 2:1) & $268,0 \pm 32,7^{\mathrm{a} 1}$ & $0,262 \pm 0,02^{\mathrm{e} 2}$ & $-36,9 \pm 7,30^{i 3}$ \\
\hline LAgNP(PC:Cho, 4:1) & $333,5 \pm 14,8^{\mathrm{b} 1}$ & $0,229 \pm 0,01^{\mathrm{f} 2}$ & $-44,2 \pm 6,99^{\mathrm{k} 3}$ \\
\hline LAgNP(PC:Cho, 8:1) & $368,4 \pm 16,7^{\mathrm{c} 1}$ & $0,271 \pm 0,02^{\mathrm{g} 2}$ & $-42,8 \pm 6,10^{\mathrm{m} 3}$ \\
\hline LAgNP(PC:Cho, 16:1) & $307,6 \pm 26,4^{\mathrm{d} 1}$ & $0,193 \pm 0,01^{\mathrm{h} 2}$ & $-42,9 \pm 7,67^{\mathrm{n} 3}$ \\
\hline
\end{tabular}

\section{Samples analyzed after 60 days}

Sample

LAgNP(PC:Cho, 2:1)

LAgNP(PC:Cho, 4:1)

LAgNP(PC:Cho, 8:1)

LAgNP(PC:Cho, 16:1)

$\begin{array}{ccc}\mathrm{MD}(\mathrm{nm}) \pm \mathrm{SD} & \mathrm{PDI} \pm \mathrm{SD} & \mathrm{ZP}(\mathrm{mV}) \pm \mathrm{SD} \\ 321,2 \pm 5,9^{\mathrm{a} 4} & 0,246 \pm 0,01^{\mathrm{e} 5} & -41,4 \pm 5,54^{\mathrm{i} 6} \\ 326,7 \pm 11,3^{\mathrm{b} 4} & 0,258 \pm 0,03^{\mathrm{f} 5} & -42,1 \pm 7,28^{\mathrm{k} 6} \\ 373,2 \pm 13,9^{\mathrm{c} 4} & 0,315 \pm 0,02^{\mathrm{g} 5} & -43,9 \pm 8,01^{\mathrm{m} 6} \\ 321,7 \pm 18,6^{\mathrm{d} 4} & 0,263 \pm 0,02^{\mathrm{h} 5} & -40,1 \pm 6,95^{\mathrm{n} 6}\end{array}$

${ }^{1} \mathrm{p}=0.0056 ;{ }^{2} \mathrm{p}=0.0016 ;{ }^{3} \mathrm{p}=0.6101 ;{ }^{4} \mathrm{p}=0.0040 ;{ }^{5} \mathrm{p}=0.0177 ;{ }^{6} \mathrm{p}=0.9240 ;{ }^{\mathrm{a}} \mathrm{p}=0.075 ;{ }^{\mathrm{b}} \mathrm{p}=0,078 ;{ }^{\mathrm{c}} \mathrm{p}=0.097 ;{ }^{\mathrm{d}} \mathrm{p}=0.089 ;{ }^{\mathrm{e}} \mathrm{p}=0.264 ;{ }^{\mathrm{f}}$ $\mathrm{p}=0.098 ;{ }^{\mathrm{g}} \mathrm{p}=0.080 ;{ }^{\mathrm{h}} \mathrm{p}=0.021 ;{ }^{\mathrm{i}} \mathrm{p}=0.047 ;{ }^{\mathrm{k}} \mathrm{p}=0.006 ;{ }^{\mathrm{m}} \mathrm{p}=0.424 ;{ }^{\mathrm{n}} \mathrm{p}=0.394$

$1,2,4,5$ Significant statistically difference $(\mathrm{p}<0,05)$

${ }^{3,6}$ There was no statistically significant difference $(\mathrm{p}>0,05)$

$\mathrm{a}, \mathrm{b}, \mathrm{c}, \mathrm{d}, \mathrm{e}, \mathrm{f}, \mathrm{g}, \mathrm{m}, \mathrm{n}$ There was no statistically significant difference $(\mathrm{p}>0,05)$

$\mathrm{h,i,k}$ Significant statistically differences $(\mathrm{p}<0,05)$ 


\section{Analysis by UV-vis spectroscopy}

Figure 3 shows the color change that occurred in the reaction media $\left(\mathrm{AgNO}_{3}\right.$ and Aloe vera gel extract solution) when submitted to different exposure times to sunlight during the formation of AgNPs.

The influence of exposure time to sunlight on the formation of AgNPs was also evaluated by UV-Vis analysis (Figure 4).
These metal nanoparticles have a surface plasmon resonance absorption in the UV-Visible region. A characteristic of these synthesized metal nanoparticles is a change in absorbance or the wavelength defines a measure of particle size, shape, and properties (Bhui et al., 2009; Sharma, Yngard, Lin, 2009).

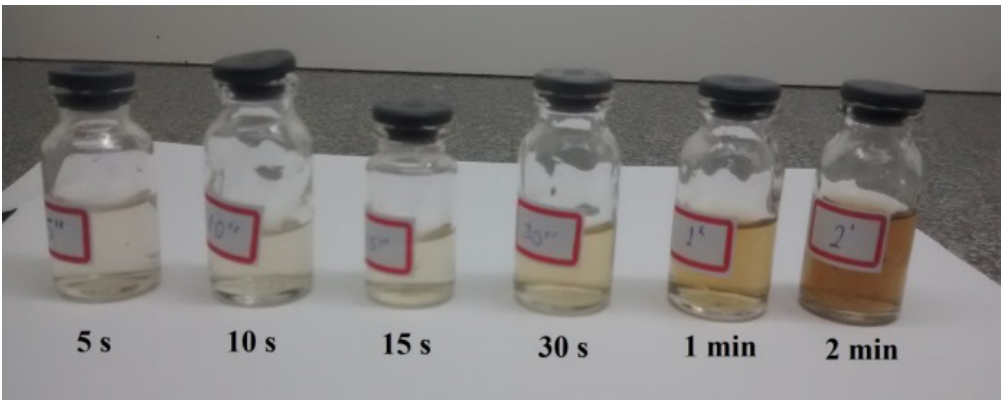

FIGURE 3 - Exposure times to sunlight of $\mathrm{AgNO}_{3}$ and Aloe vera gel extract solutions. From left to right: 5 seconds, 10 seconds, 15 seconds, 30 seconds, 1 minute and 2 minutes.

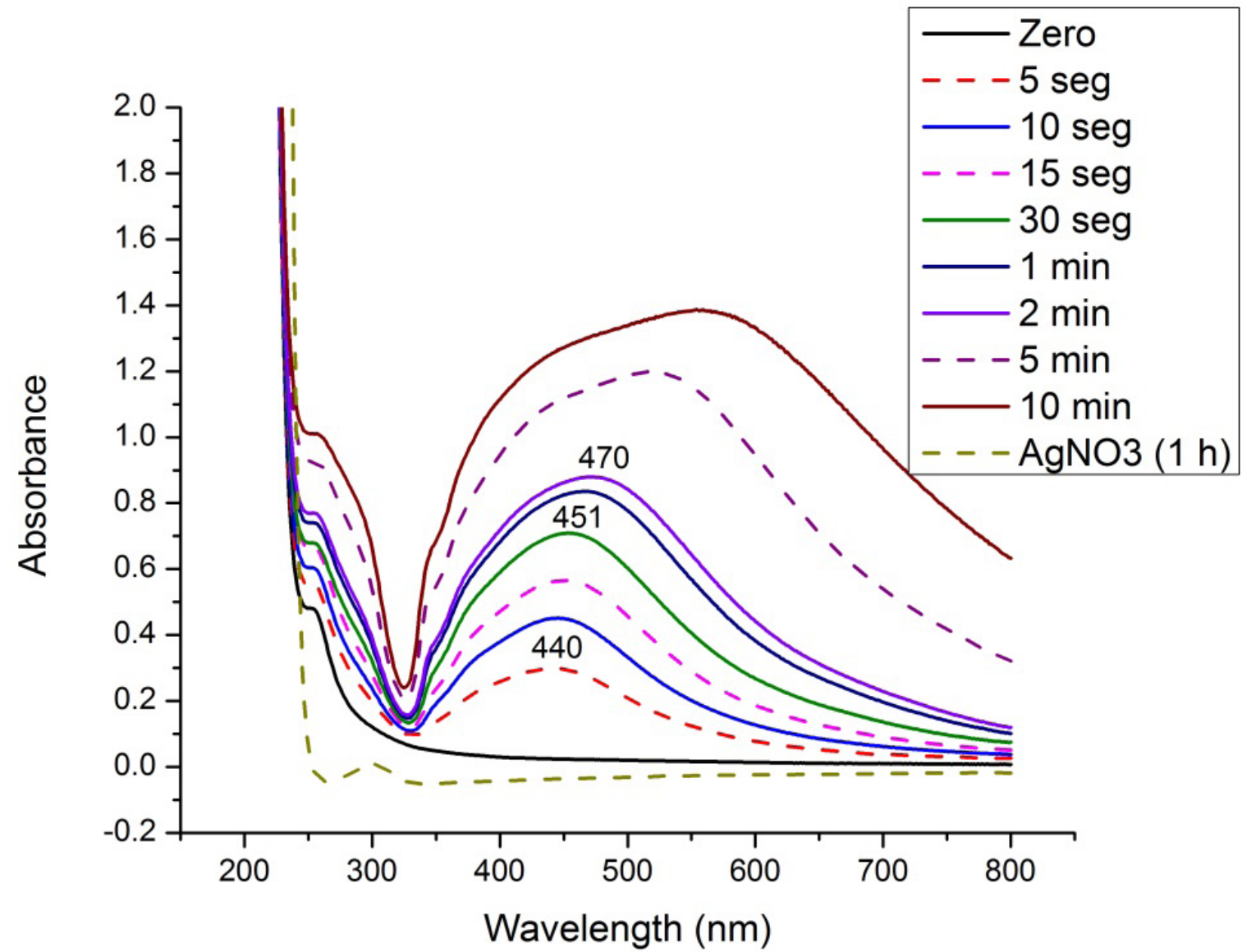

FIGURE 4 - UV-Vis absorption spectra of control solution $\left(\mathrm{AgNO}_{3}\right)$ and the reaction media $\left(\mathrm{AgNO}_{3}\right.$ and Aloe vera gel extract) at different times of exposure to sunlight. 
It can be observed in Figure 4, the presence of the silver surface plasmon resonance band at $451 \mathrm{~nm}$, which occurred around 30 seconds, is indicative of the spherical shape of the AgNPs and of a size smaller than $100 \mathrm{~nm}$ (Cardoso et al., 2014). After this time, the AgNPs begin to agglomerate generating larger particles and this effect is observable in the UV-Vis spectra, where AgNPs exposed for more than 2 minutes exhibit a shift to longer wavelengths. The band displacement depends on the particle size, the chemical environment, the adsorbed species on the surface and the dielectric constant (Sharma, Yngard, Lin, 2009).

AgNPs synthesized before two minutes show an absorption peak at approximately 440-470 $\mathrm{nm}$. This behavior indicates that the samples have homogeneous populations of size (Paredes, 2011).

According to Paredes (2011) the 5 and 10-minute spectra indicated the large size and with different shapes of AgNPs, which may be triangular or square shapes. The increase in absorbance in the spectrum suggests that there was an aggregation of AgNPs. Similarly, in this work, it is observed that the peak becomes larger as the time of sun exposure increases, revealing a heterogeneous distribution of sizes (Cruz et al., 2012).

No absorption peaks were observed in the samples without sunlight exposure, the silver nitrate solution without extract also did not show the surface plasmon resonance band. This means that sunlight and Aloe vera gel extract solution play an important role in the formation of AgNPs.

Altering the size of the spherical particles may induce small changes in the position of the absorption peak in UV-vis (Barani et al., 2011, 2010). Thus, loading of AgNPs into liposomes provides a stabilizing effect but modifies the absorption band of the surface plasmon resonance (Figure 5). AgNP30s showed absorbance at 451. The incorporation of AgNPs into liposome caused a slight shift in the absorption spectrum and LAgNP8:1 obtained lower absorption.

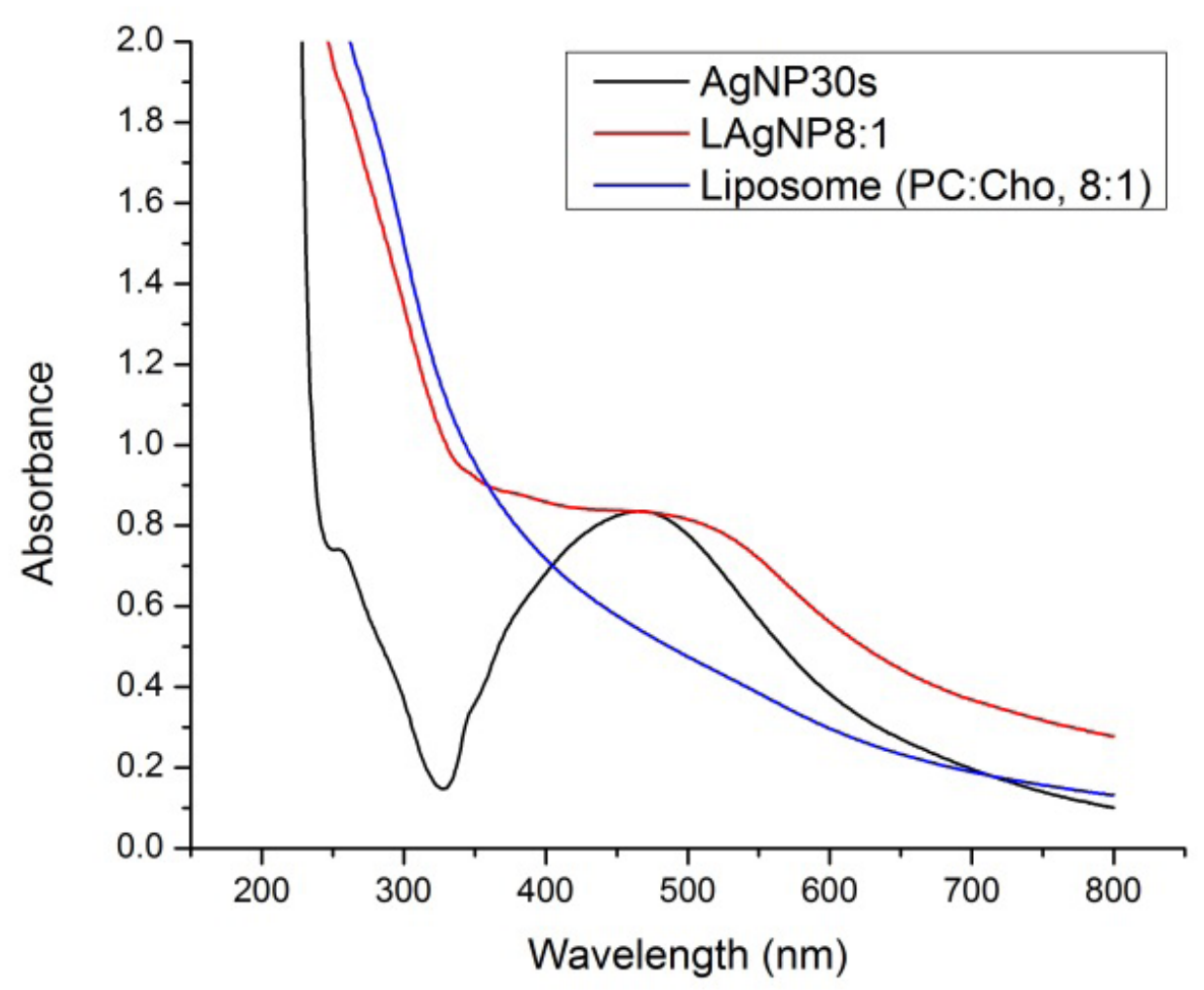

FIGURE 5 - UV-Vis absorption spectra of the AgNP30s and LAgNP8:1 solutions. 


\section{Scanning Electron Microscopy (SEM)}

The morphological and surface evaluation of AgNPs synthesized at various amounts of sun exposure time are shown in Figure 6.

The images of the photomicrographs show that the AgNPs have amorphous, almost spherical appearance. It can also be observed that AgNPs obtained from 1 minute of sun exposure are agglomerated. The sizes of the individual AgNPs measured by the equipment software indicated sizes between 40 and $70 \mathrm{~nm}$.

Considering the above-mentioned results, the AgNP30s were chosen to be encapsulated in liposomes because they had an absorption peak at $451 \mathrm{~nm}$ in UVvis (Figure 4), PDI of 0.48 and $\mathrm{ZP}$ of $-18.96 \mathrm{mV}$ and did not show agglomeration in SEM images.

The results obtained by SEM for the LAgNPs are shown in Figure 7.
Liposomes are presented as spherical and uniform structures in all formulations. The size of the liposomes observed in the images, from $156 \mathrm{~nm}$ to $400 \mathrm{~nm}$ is greater than the AgNPs (between 40 and $70 \mathrm{~nm}$ ), indicated in Figure 6.

Eid and Azzazy (2014) also obtained spherical morphology of the liposomes, which have particles with a size of 250-400 $\mathrm{nm}$.

The LagNP8:1 was analyzed with energy dispersive X-ray (EDX) spectrum analysis (Figure 8). The EDX study demonstrated that the LAgNPs possessed silver nanoparticles and the quantitative analysis showed silver content in the examined sample was about $8.62 \%$. The presence of phosphorus $(0.09 \%)$ due to the phosphate groups of phospholipids and the carbon (39.25\%) present in the fatty acid chains, belong to the bilipidic membrane of liposomes. The aluminum belongs to the sample support.
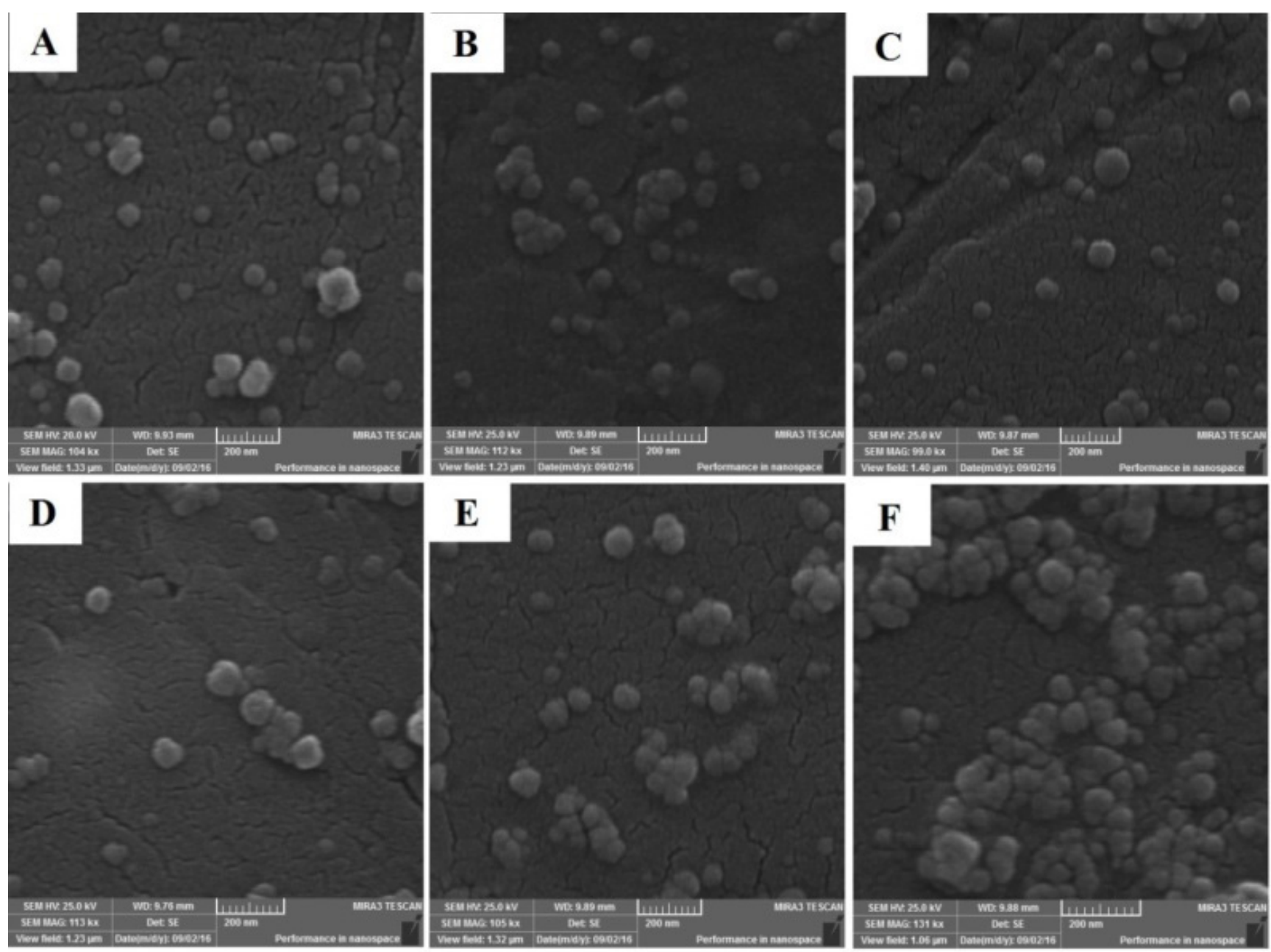

FIGURE 6 - Microphotographs obtained by SEM of the AgNPs synthesized during A) 5 seconds, B) 10 seconds, C) 15 seconds, D) 30 seconds, E) 1 minute and F) 2 minutes exposure to sunlight. 
Joel Toribio Espinoza, Robson Schimandeiro Novak, Cássia Gonçalves Magalhães, Jane Manfron Budel, Barbara Justus, Melissa Marques Gonçalves, Patricia Mathias Döll Boscardin, Paulo Vitor Farago, Josiane de Fátima Padiha De Paula

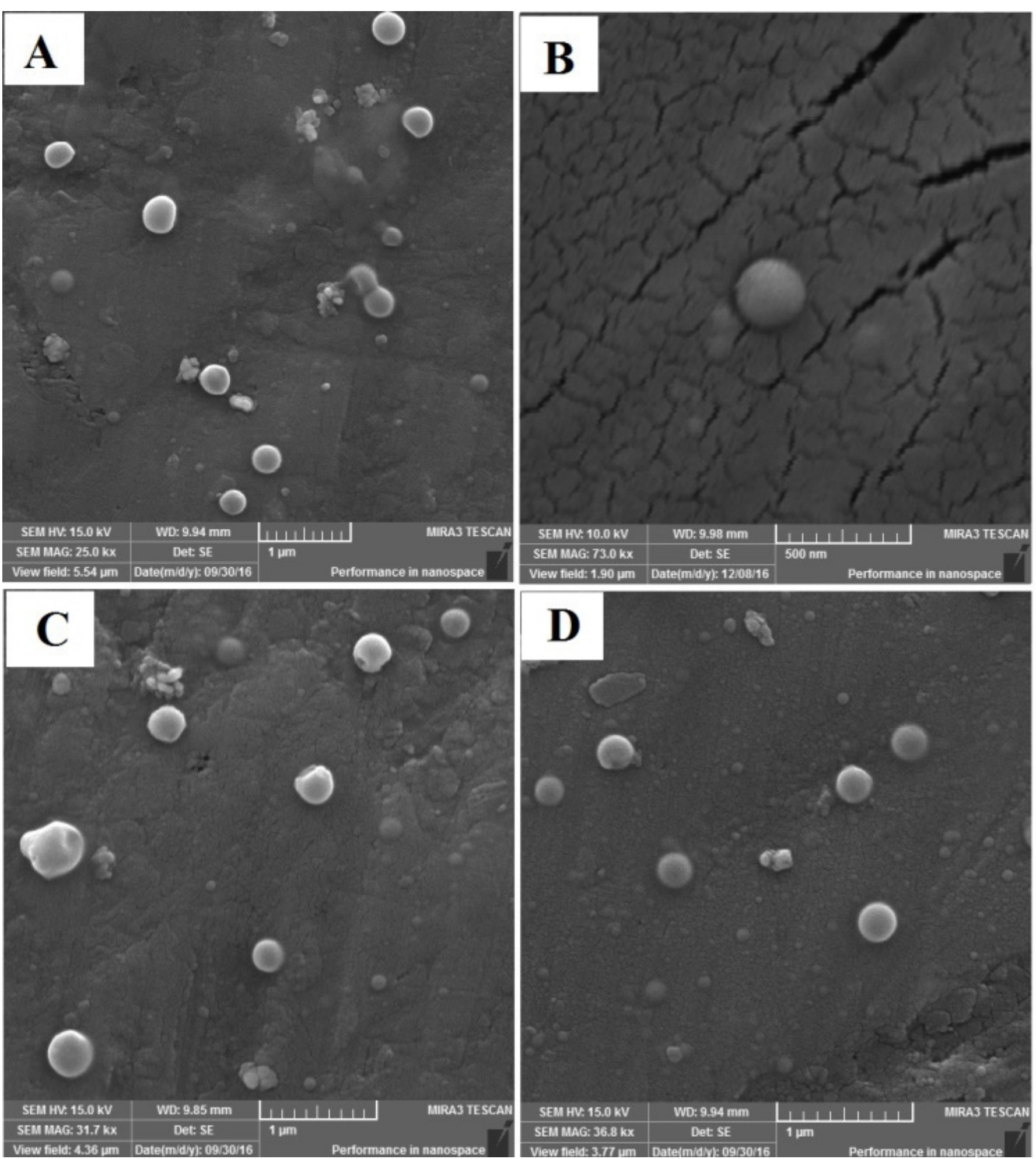

FIGURE 7 - Microphotographs obtained by SEM of LAgNP in different molar ratios of PC:Col. A) 2: 1, B) 4: 1, C) 8: 1 and D) 16: 1 . 


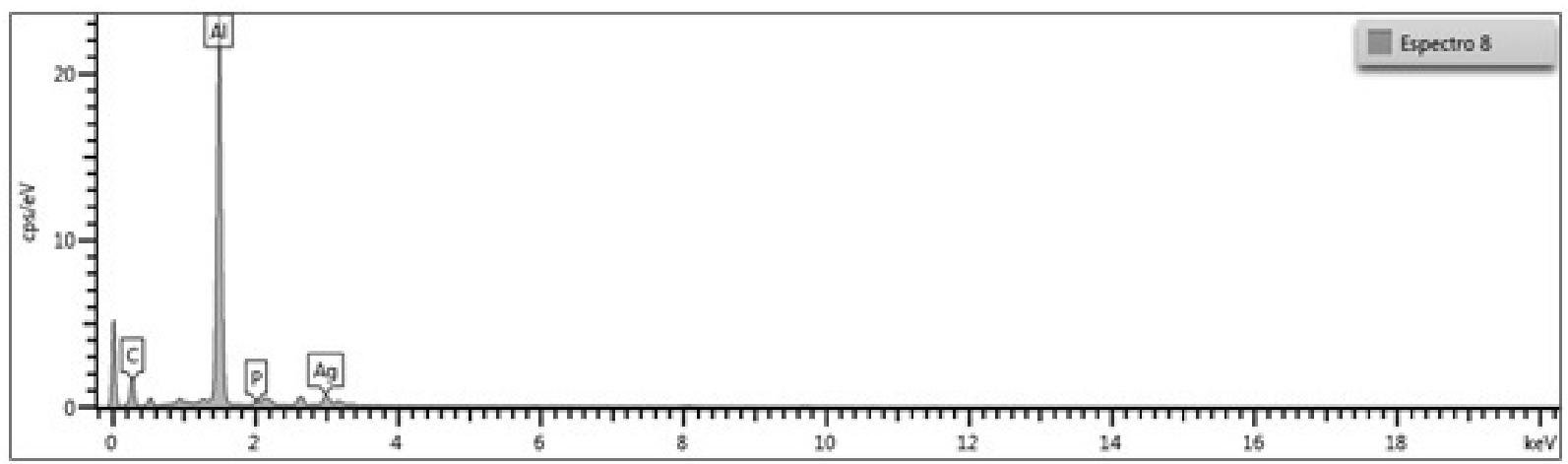

\begin{tabular}{|r|r|r|}
\hline ELEMENTO & WT\% & SIGMA WT\% \\
$\mathrm{C}$ & 39.25 & 0.48 \\
\hline $\mathrm{AL}$ & 52.05 & 0.43 \\
\hline $\mathrm{P}$ & 0.09 & 0.07 \\
\hline $\mathrm{AG}$ & 8.62 & 0.22 \\
\hline Total: & 100 &
\end{tabular}

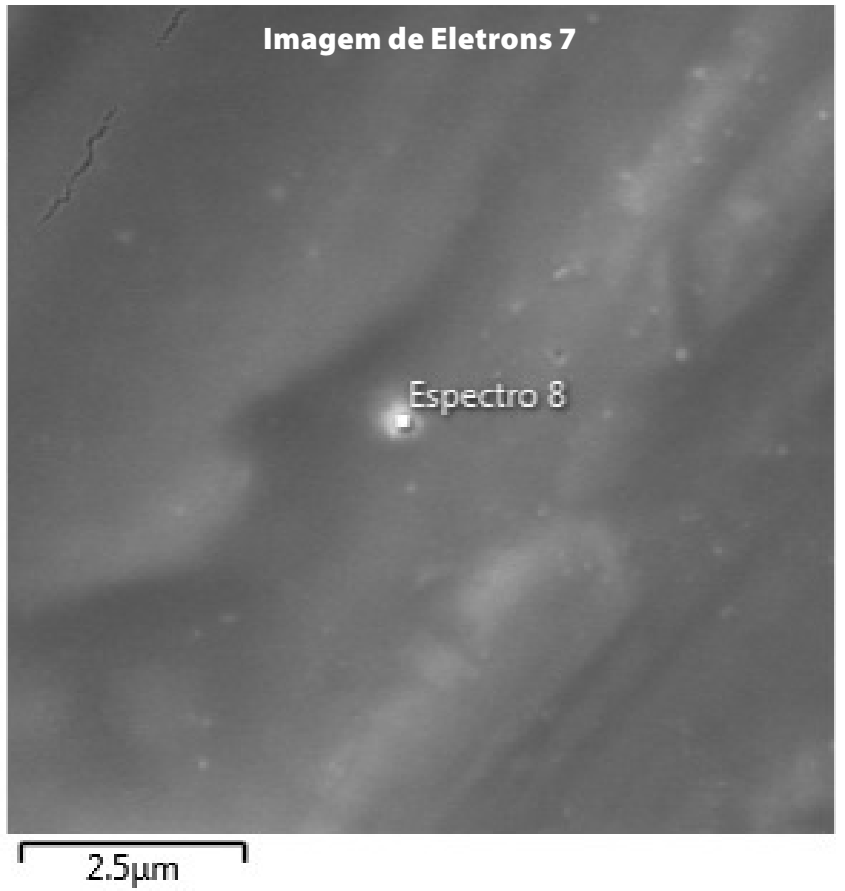

FIGURE 8 - EDX spectrum from selected area of the Liposome LAgNP8:1

\section{Analysis by Fourier-transform infrared spectroscopy (FTIR)}

The spectra obtained by FTIR allow to characterize the functional groups that could be involved in the synthesis of AgNP30s and these are shown in Figure 9. Two regions are observed in which the intensity of the bands was decreased in 1646 and $3457 \mathrm{~cm}^{-1}$ corresponding to bonds of type $\mathrm{C}=\mathrm{O}$ and $\mathrm{OH}$ respectively.

These results were similar to those found by Sadhasivam and Durairaj (2014), where the band at
$3454.91 \mathrm{~cm}^{-1}$ showed $\mathrm{O}-\mathrm{H}$ bond elongation and at $1643.78 \mathrm{~cm}^{-1}$ showed $\mathrm{C}=\mathrm{O}$ bond elongation. The aforementioned authors also worked with Aloe vera as a reducing agent.

The reduction of the intensity in the bands implies the participation of these bonds in the formation of silver nanoparticles. Cardoso et al. (2014), mentioned that the band due to $\mathrm{C}=\mathrm{O}$ (amine I at $1652.84 \mathrm{~cm}^{-1}$ ) in the AgNP30s spectrum showed a low intensity, indicating that this group was possibly involved in the reduction and stabilization of AgNP30s. 


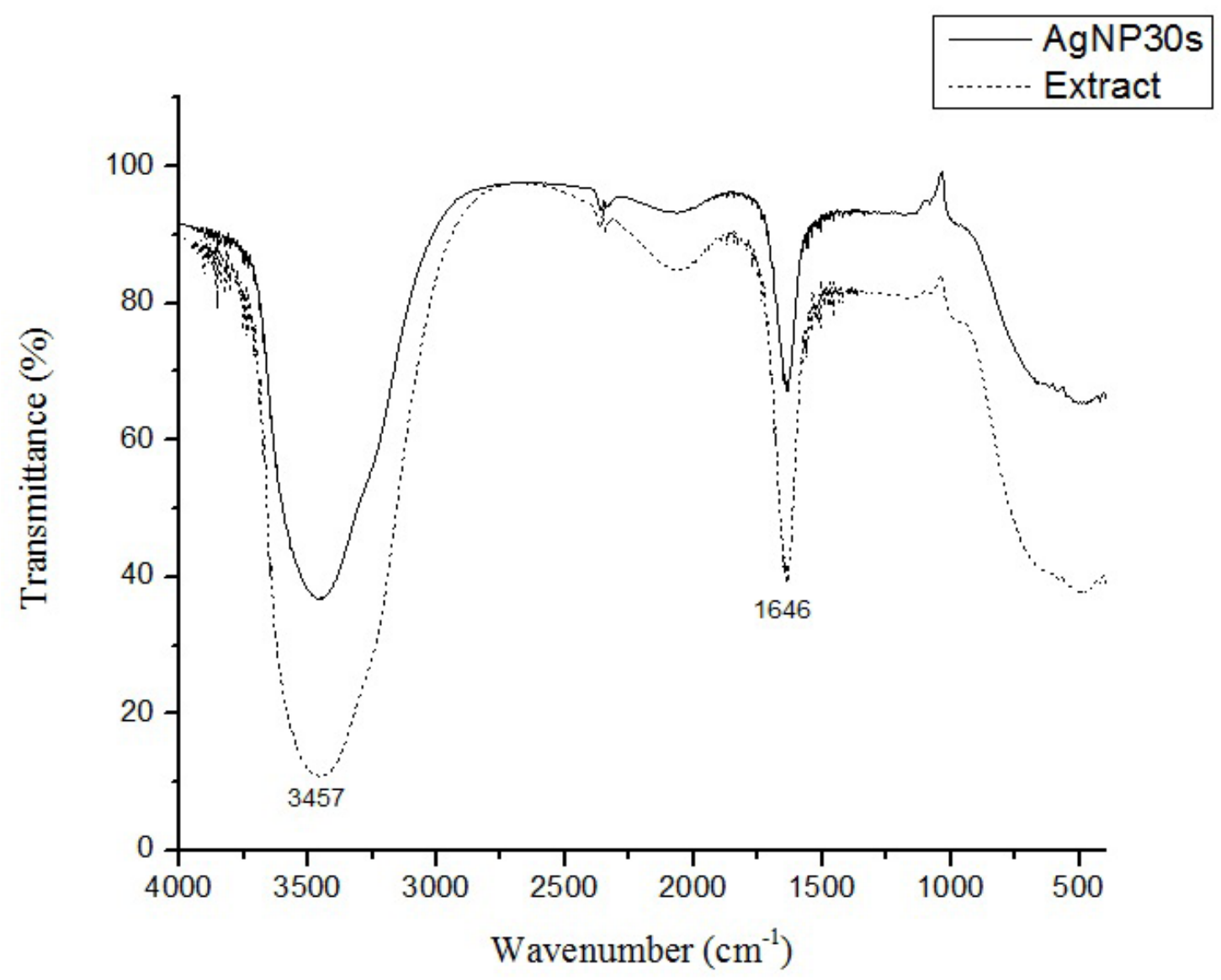

FIGURE 9 - FTIR Spectrum of Aloe vera Extract and AgNP30s.

The existence of some phenolic, terpenoid or protein components that are bound to the AgNP30s surfaces remains, although the extract has been diluted many times. The stability of the AgNP30s can be justified by the adhesion of the carboxylic and free amino groups on the surface of the AgNP30s.

Bands of functional groups such as -CO-C- $(1,720-$ $\left.1,700 \mathrm{~cm}^{-1}\right)$, $-\mathrm{CO}-\left(\sim 1,200 \mathrm{~cm}^{-1}\right)$ and $-\mathrm{C}=\mathrm{C}-(1,600$, $1,580,1,500$ and $\left.1,450 \mathrm{~cm}^{-1}\right)$ are derivatives of heterocyclic components and the amide bands are derived from proteins present in the Aloe vera leaf extract and are the nanoparticle cover ligand (Zhang et al., 2013).

Figure 10 shows the FTIR spectrum of cholesterol. An intense and wide band at $3418 \mathrm{~cm}^{-1}$ characteristics of the O-H alcohol group is observed. The bands at 2939 and $2864 \mathrm{~cm}^{-1}$ refer to the asymmetric and symmetrical stretching, respectively, of the methyl-CH 3 group. The 1462 and $1378 \mathrm{~cm}^{-1}$ bands are characteristic of the $-\mathrm{CH} 2$ bond and finally the $1053 \mathrm{~cm}^{-1}$ band corresponds to the $\mathrm{C}-\mathrm{O}$ bond.

The bands in the cholesterol spectrumare maintained when this compound is bound to phosphatidylcholine in the formation of liposomes, thus indicating that there was no chemical interaction with phosphatidylcholine (PC). However, there are no considerable displacements in the liposomes formed, an effect that occurs when cholesterol is added to the liposomes, affecting the - $\mathrm{CH} 3$ band (Mahmoud et al., 2008).

To represent the LAgNP8: 1 spectra, the spectra of AgNP30s and Liposomes without silver (PC: COL 8: 1) were compared in Figure 10. The spectra obtained showed absorption bands in the same wavenumbers observed for the respective samples. Therefore, it is possible to establish that no chemical linkage between liposomes and AgNPs was formed during the synthetic processes. 


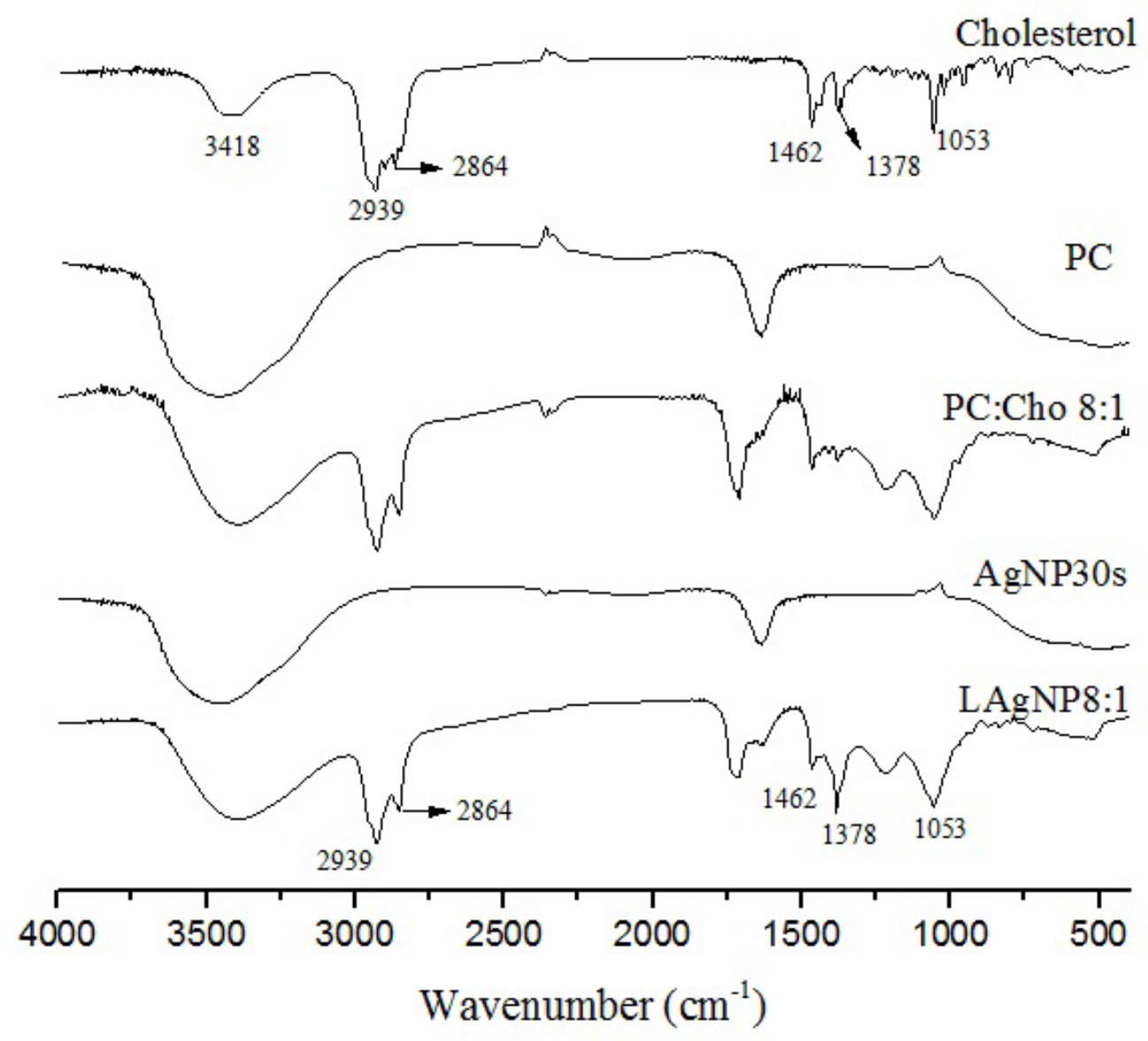

FIGURE 10 - FTIR spectra of LAgNP, AgNP, cholesterol, PC, and PC:Cho8:1.

\section{Determination of silver by flame atomic absorption spectrometry}

The quantification of Silver in solutions of AgNP30s or LAgNPs by flame atomic absorption spectrometry was determined by constructing the analytical curve in quintuplicate and using five levels of concentration 2, $4,6,8$ and $10 \mathrm{ppm}$, so the equation of linear regression and the correlation coefficient (r), by the least squares method, generated an $\mathrm{r} 2=0.9987$.

\section{Determination of liposome encapsulation efficiency}

The efficiency of encapsulation of silver nanoparticles in liposomes was evaluated using the analytical method of flame atomic absorption spectrometry. The results are shown in Table III.
TABLE III - Efficiency of liposome encapsulation
Liposome

LAgNP(PC:Cho, 2:1)

LAgNP(PC:Cho, 4:1)

LAgNP(PC:Cho, 8:1)

$\operatorname{LAgNP}(\mathrm{PC}:$ Cho, 16:1)
Encapsulation Efficiency

(\%) \pm SD

$58,83 \pm 29,69$

$54,90 \pm 14,56$

$53,35 \pm 9,34$

$51,81 \pm 19,31$
The literature points out as one of the main disadvantages in traditional methods of liposome preparation its low encapsulation rate ( $\mathrm{Li}$ and An, 2014). However, the technique used to encapsulate AgNP30s in liposomes was effective, with encapsulation rates ranging from 51.81 to $58.83 \%$. 
Depending on the methodology, vesicle size, lipid components and drug type, encapsulation values may range from less than $1 \%$ to $100 \%$ of the drug used (Gregoriadis, 1995).

\section{CONCLUSIONS}

The green synthesis method with Aloe vera gel extract and sunlight was found to be viable, low impact on the environment and easy to perform.

The time of 30 seconds of solar exposure was the most adequate to obtain the AgNPs, with appropriate sizes between 40 and $70 \mathrm{~nm}$ observed in SEM, polydisperse and with a zeta potential of $-18.96 \mathrm{mV}$.

Characterization by UV Vis spectroscopy demonstrated the surface plasmon resonance band, characteristic of the formation of silver nanoparticles, and FTIR spectroscopy showed the presence of possible functional groups involved in the reduction of ionic silver.

The liposomes developed by the modified reverse phase evaporation method had an average diameter of 321 to $373 \mathrm{~nm}$, a zeta potential of around $-40 \mathrm{mV}$, and a polydispersity index of 0.2 , indicating homogeneity of sizes.

AgNPs were encapsulated in liposomes with cholesterol, with good encapsulation rate and greater stability.

In this way, it can be concluded that the objectives proposed in the present work of technological development of silver nanoparticles encapsulated in liposomes were successfully achieved.

\section{ACKNOWLEDGEMENTS}

The authors are thankful to CAPES, the UEPG and LABMU- UEPG by the support offered.

\section{REFERENCES}

Alarcon EI, Udekwu K, Skog M, Pacioni NL, Stamplecoskie $\mathrm{KG}$, González-Béjar $\mathrm{M}$, et al. The biocompatibility and antibacterial properties of collagen-stabilized, photochemically prepared silver nanoparticles. Biomaterials. 2012;33(19):4947-56.

Aramaki K, Watanabe Y, Takahashi J, Tsuji Y, Ogata A. Charge boosting effect of cholesterol on cationic liposomes. Colloids Surfaces A Physicochem Eng Asp. 2016;506:732-8.
Ashraf JM, Ansari MA, Khan HM, Alzohairy MA, Choi I. Green synthesis of silver nanoparticles and characterization of their inhibitory effects on AGEs formation using biophysical techniques. Sci Rep. 2016;6:20414.

Barani H, Montazer M, Samadi N, Toliyat T. Nano silver entrapped in phospholipids membrane: synthesis, characteristics and antibacterial kinetics. Mol Membr Biol. 2011;28(4):206-15.

Barani H, Montazer M, Toliyat T, Samadi N. Synthesis of Ag-liposome nano composites. J Liposome Res. 2010;20(4): 323-9.

Bhui DK, Bar H, Sarkar P, Sahoo GP, De SP, Misra A. Synthesis and UV-vis spectroscopic study of silver nanoparticles in aqueous SDS solution. J Mol Liq. 2009;145(1):33-7.

Cardoso VS, Quelemes PV, Amorin A, Primo F, Gobo G, Tedesco AC, et al. Collagen-based silver nanoparticles for biological applications: synthesis and characterization. J Nanobiotechnol. 2014;12:36.

Cruz DA, Rodríguez MC, López JM, Herrera VM, Orive AG, Creus AH. Nanopartículas metálicas y plasmones de superficie: Una relación profunda. Av En Ciencias Ing. 2012;3(2):67-78.

Eid KA, Azzazy HM. Sustained broad-spectrum antibacterial effects of nanoliposomes loaded with silver nanoparticles. Nanomedicine. 2014;9(9):1301-10.

Escobar VE. Síntesis y caracterización de nanopartículas de plata por espectroscopia de infrarrojos (FT-IR), UV-Vis, absorción atómica de llama (FAAS) y microscopía de barrido electrónico (SEM). Pontificia Universidad Católica Del Ecuador; 2015.

Gade A, Gaikwad S, Duran N, Rai M. Green synthesis of silver nanoparticles by Phoma glomerata. Micron. 2014;59:52-9.

Gregoriadis G. Engineering liposomes for drug delivery: progress and problems. Trends Biotechnol. 1995;13(12): 527-37.

Guo D, Zhang J, Huang Z, Jiang S, Gu N. Colloidal silver nanoparticles improve anti-leukemic drug efficacy via amplification of oxidative stress. Colloids Surfaces B Biointerfaces. 2015;126:198-203.

Johnston HJ, Hutchison GR, Christensen FM, Peters S, Hankin S, Aschberger K, et al. A critical review of the biological mechanisms underlying the in vivo and in vitro toxicity of carbon nanotubes: The contribution of physicochemical characteristics. Nanotoxicology. 2010;4(2):207-46. 
Katagiri K, Hashizume M, Ariga K, Terashima T, Kikuchi JI. Preparation and characterization of a novel organic-inorganic nanohybrid "cerasome" formed with a liposomal membrane and silicate surface. Chem Eur J. 2007;13(18):5272-81.

Keat CL, Aziz A, Eid AM, Elmarzugi NA. Biosynthesis of silver nanoparticles and silver nanoparticles. Bioresour Bioprocess. 2015;2:47.

Kumar V, Bano D, Mohan S, Singh DK, Hasan SH. Sunlightinduced green synthesis of silver nanoparticles using aqueous leaf extract of Polyalthia longifolia and its antioxidant activity. Mater Lett. 2016a;181:371-7.

Kumar V, Gundampati RK, Singh DK, Jagannadham MV, Sundar S, Hasan SH. Photo-induced rapid biosynthesis of silver nanoparticle using aqueous extract of Xanthium strumarium and its antibacterial and antileishmanial activity. J Ind Eng Chem. 2016b;37:224-36.

Lacatusu I, Badea N, Stan R, Meghea A. Novel bio-active lipid nanocarriers for the stabilization and sustained release of sitosterol. Nanotechnology. 2012;23(45):455702.

Li J, An X. Photoinduced drug release from complexes of liposome and fl uorescent silver nanoparticles. RSC Adv. 2014;19:9476-9.

Liu J, Yu S, Yin Y, Chao J. Methods for separation, identification, characterization and quantification of silver nanoparticles. TrAC Trends Anal Chem. 2012;33:95-106.

Low WL, Martin C, Hill DJ, Kenward MA. Antimicrobial efficacy of liposome-encapsulated silver ions and tea tree oil against pseudomonas aeruginosa, staphylococcus aureus and candida albicans. Lett Appl Microbiol. 2013;57(1):33-9.

Mahmoud SS, Gehman JD, Azzopardi K, Robins-Browne RM, Separovic F. Liposomal phospholipid preparations of chloramphenicol for ophthalmic applications. J Pharm Sci. 2008;97(7):2691-701.

Maillard M, Huang P, Brus L. Silver nanodisk growth by surface plasmon enhanced photoreduction of absorbed Ag. Nano Lett. 2003;3(11):1611-5.

Mexico SE. Análisis de Agua - Determinación de Metales por Absorción Atómica en aguas naturales, potables, residuales y residuales tratadas - Método de Prueba. México D.F.; 2001.

Mukha IP, Eremenko AM, Smirnova NP, Mikhienkova AI, Korchak GI, Gorchev VF, et al. Antimicrobial activity of stable silver nanoparticles of a certain size. Appl Biochem Microbiol. 2013;49(2):199-206.
Neves AR, Lúcio M, Martins S, Costa Lima JL, Reis S. Novel resveratrol nanodelivery systems based on lipid nanoparticles to enhance its oral bioavailability. Int $\mathrm{J}$ Nanomedicine. 2013;8:177-87.

Paluri SLA. Synthesis, characterization and manipulation of creighton silver nanoparticles for future cytotoxicity studies. Wright State University; 2011.

Panacek A, Kolar M, Vecerova R, Prucek R, Soukupova J, Krystof V, et al. Antifungal activity of silver nanoparticles against Candida spp. Biomaterials. 2009;30(31):6333-40.

Paredes DJ.Estudio del efecto antibacteriano de nanopartículas de plata sobre Escherichia coli Y Staphylococcus aureus. Universidad Industrial de Santander; 2011.

Ragaseema VM, Unnikrishnan S, Kalliyana Krishnan V, Krishnan LK. The antithrombotic and antimicrobial properties of PEG-protected silver nanoparticle coated surfaces. Biomaterials. 2012;33(11):3083-92.

Ramírez MAC. Evaluación de la cinética de Distribución y Toxicidad de las Nanopartículas de Plata. Universidad Autónoma de Neuvo León; 2010.

Sadhasivam L, Durairaj JR. Evaluation profile of silver nanoparticle synthesized by aloe vera extract. Int J ChemTech Res. 2014;6(9):4379-85.

Sharma VK, Yngard RA, Lin Y. Silver nanoparticles: Green synthesis and their antimicrobial activities. Adv Colloid Interface Sci. 2009;145(1-2):83-96.

Sulaiman GM, Mohammed WH, Marzoog TR, Al-Amiery AAA, Kadhum AAH, Mohamad AB. Green synthesis, antimicrobial and cytotoxic effects of silver nanoparticles using Eucalyptus chapmaniana leaves extract. Asian Pac J Trop Biomed. 2013;3(1):58-63.

Szoka F, Papahadjopoulos D. Procedure for preparation of liposomes with large internal aqueous space and high capture by reverse-phase evaporation. Proc Natl Acad Sci U S A. 1978;75(9):4194-8.

Tang B, Sun L, Li J, Zhang M, Wang X. Sunlight-driven synthesis of anisotropic silver nanoparticles. Chem Eng J. 2014;260:99-106.

Zhang Y, Cheng X, Zhang Y, Xue X, Fu Y. Biosynthesis of silver nanoparticles at room temperature using aqueous aloe leaf extract and antibacterial properties. Colloids Surfaces A Physicochem Eng Asp. 2013;423:63-8.

Zhang Y, Yang D, Kong Y, Wang X, Pandoli O, Gao G. Synergetic antibacterial effects of silver nanoparticles @ 
Joel Toribio Espinoza, Robson Schimandeiro Novak, Cássia Gonçalves Magalhães, Jane Manfron Budel, Barbara Justus, Melissa Marques Gonçalves, Patricia Mathias Döll Boscardin, Paulo Vitor Farago, Josiane de Fátima Padiha De Paula

Aloe Vera Prepared via a green method. Nano Biomed Eng. 2010;2(4):252-7.

Zhu D, Wang Z, Zong S, Chen $\mathrm{H}$, Wu X, Pei Y, et al. $\mathrm{Ag} @ 4$ ATP-coated liposomes: SERS traceable delivery vehicles for living cells. Nanoscale. 2014;6:8155-61.
Received for publication on $09^{\text {th }}$ August 2018

Accepted for publication on $08^{\text {th }}$ January 2019 